\title{
Efektivitas intervensi berbasis mindfulness dalam meningkatkan resiliensi di tempat kerja: Studi meta analisis
}

\author{
Ni Made Wulan Widyaswari Anasta Putri ${ }^{(1)}$, Ananta Yudiarso ${ }^{(2)}$ \\ ${ }^{(1),(2)}$ Fakultas Psikologi, Universitas Surabaya, Surabaya, Indonesia
}

Every individual should develop resilience to become adapted to the new work challenges that are more complex and competitive in the current era. Resilience is an individual's ability to recover from stress. Mindfulness has been found to increase resilience in the existing research. The goal of our research was to examine the effectiveness of mindfulness-based interventions to increase resilience among working individuals. We reviewed 14 research journals as a source of meta-analysis with 759 participants in total. Data processing was based on sample size $(N)$, mean $(M)$, and standard deviation $(S D)$ using the random effect model through which we obtained the medium heterogeneity $\left(I^{2}\right)=32 \%$ and Hedges'g standardized mean difference $(S M D)=$ $.62(95 \%$ confidence interval $[\mathrm{Cl}]=.43$ to .80$)$. These findings imply that mindfulness is less effective in increasing the working individuals' resilience.

Keywords: meta-analysis, mindfulness intervention, resilience at work

Untuk bisa adaptif menghadapi tantangan kerja baru yang semakin kompleks dan kompetitif di era saat ini, setiap indvidu memerlukan daya tahan atau relisiensi. Resiliensi merupakan kemampuan individu untuk pulih dari stres. Dalam riset-riset debelumnya, mindfullness telah ditemukan efektif meningkatkan resiliensi. Penelitian ini bertujuan untuk meneliti efektivitas intervensi berbasis mindfulness untuk meningkatkan resiliensi pada individu yang bekerja. Kami mereview 14 jurnal penelitian sebagai sumber dari penelitian meta analisis dengan jumlah partisipan sebanyak 759. Data diolah atas dasar ukuran sampel $(N)$, rata-rata $(M)$, dan deviasi standar $(S D)$ dengan menggunakan random effect model, yang menghasilkan nilai heterogenity $\left(\mathrm{I}^{2}\right)=32 \%$ dan Hedges'g (SMD) 0.62 (95\% confidence interval $[\mathrm{Cl}]=0.43$ sampai dengan 0.80$)$ yang berada dalam kategori sedang. Temuan-temuan tersebut mengimplikasikan bahwa mindfulness kurang efektif untuk meningkatkan resiliensi individu yang bekerja.

Kata kunci: intervensi mindfulness, meta-analisis, resiliensi di tempat kerja

MEDIAPSI, 2021, Vol. 7(1), 27-36, DOI: https://doi.org/10.21776/ub.mps.2021.007.01.4

Received: 13-09-2020. Revised: 22-01-2021. Accepted: 08-01-2021. Published online: 24-06-2021

Handling Editor: Halimatus Sakdiah, UIN Antasari, Banjarmasin, Indonesia

*Corresponding author: Ni Made Wulan Widyaswari Anasta Putri, Fakultas Psikologi, Universitas Surabaya, Surabaya, Indonesia. E-mail: s154119518@ student.ubaya.ac.id

This work is licensed under a Creative Commons Attribution-NonCommercial 4.0 International License.

How to cite this article in accordance with the American Psychological Association (APA) $7^{\text {th }}$ guidelines:

Putri, N. M. W. W. A., \& Yudiarso, A. (2021). Efektivitas intervensi berbasis mindfulness dalam meningkatkan resiliensi di tempat kerja: Studi meta analisis. MEDIAPSI, 7(1), 27-36. https://doi.org/10.21776/ub.mps.2021.007.01.4

\section{Pendahuluan}

Perkembangan dunia kerja yang dinamis dipengaruhi oleh perkembangan teknologi yang konstan, lingkungan yang kompleks, kompetitif, dan selalu berubah yang 
berujung pada beban kerja yang berat dan memiliki tenggang waktu tertentu (Johnson dkk., 2020). Karyawan cenderung mendapatkan tekanan di tempat kerja dan peristiwa buruk yang mungkin dialami selama bekerja (Hartwig dkk., 2020).

Peristiwa yang buruk tidak hanya berpotensi mengganggu kinerja karyawan tetapi juga menyebabkan ketegangan mental atau fisik yang serius bagi karyawan. Salah satu tantangan besar bagi pemimpin organisasi adalah memperhatikan kesejahteraan karyawan (Johnson dkk., 2020). Resiliensi memiliki potensi untuk mempertahankan kinerja dan kesejahteraan karyawan dalam menghadapi kesulitan (Hartwig dkk., 2020).

Meningkatkan resiliensi tidak hanya meningkatkan kesejahteraan individu, tetapi juga dapat membantu individu dalam mengurangi stres yang dialami dan meningkatkan hubungan positif dengan rekan kerja (Barrat, 2018). Secara umum, resiliensi adalah sifat pribadi yang membantu individu mengatasi kesulitan dalam hidup, mencapai penyesuaian dan pengembangan yang baik dalam keadaan yang sulit (Bajaj \& Pande, 2016). Resiliensi di tempat kerja adalah kemampuan karyawan untuk mengelola dan secara positif mengatasi kejadian buruk di tempat kerja (Fletcher \& Sarkar, 2013).

Menurut Aherne dkk. (2016), mindfulness menunjukkan potensi untuk menumbuhkan resiliensi seseorang dengan lebih baik. Memberikan pelatihan mindfulness pada karyawan di tempat kerja bermanfaat untuk melatih fokus perhatian, meningkatkan konsentrasi, keseimbangan emosional, self-awareness, relasi dengan rekan kerja yang baik dan peningkatan kesejahteraan karyawan (Johnson dkk., 2020). Karyawan yang memiliki pengalaman positif yang diperoleh dari pelatihan mindfulness dapat mengelola dan mengendalikan ketegangan, stres dan konflik yang dialami saat bekerja dan mampu mengidentifikasi masalah terkait pekerjaan dengan lebih baik (Johnson dkk., 2020).

Mindfulness didefinisikan sebagai memberikan perhatian secara penuh dengan sengaja pada pengalaman saat ini, dengan sikap terbuka dan menerima tanpa menghakimi (Burton dkk., 2017; Huang dkk., 2015). Intervensi berbasis mindfulness awalnya dikembangkan dalam konteks klinis (Lomas dkk., 2019). Namun, selama beberapa tahun terakhir penerapan intervensi berbasis mindfulness dalam konteks pekerjaan semakin meningkat.

Penelitian yang dilakukan oleh Colgan dkk. (2019) menunjukkan intervensi mindfulness berbasis wellness dan resilience (MBWR) merupakan metode yang layak dan dapat digunakan untuk mengintegrasikan mindfulness, resiliensi dan memberikan manfaat dalam peningkatan perawatan pasien. Temuan tersebut senada dengan penelitian Schroeder dkk. (2016) yang menemukan bahwa intervensi berbasis mindfulness atau mindfulness-based intervention (MBI) berdampak positif pada kesehatan dokter, resiliensi dan berpotensi meningkatkan perawatan pasien.

Beberapa studi telah meneliti manfaat pelatihan mindfulness di antara kelompok tertentu, termasuk tenaga kesehatan, mahasiswa, penderita kanker, mahasiswa, pemadam kebakaran dan pekerja kantoran. Semakin banyak organisasi saat ini menawarkan pelatihan mindfulness untuk meningkatkan kesejahteraan karyawan. 
Namun, penelitian tentang efektivitas intervensi berbasis mindfulness di tempat kerja masih terbatas (Kersemaekers dkk., 2018).

Sebagai contoh, hasil meta analisis yang dilakukan Lomas dkk. (2019) menunjukkan nilai effect size yang besar pada intervensi mindfulness terhadap stress, anxiety dan distress, dan small to medium effect size terhadap depression, job performance, compassion dan empati dan positive well-being. Dibandingkan dengan kelompok kontrol, kelompok yang mendapat intervensi secara signifikan lebih rendah dalam tekanan psikologi, kelelahan yang berkepanjangan dan stres yang dirasakan setelah menjalankan pelatihan mindfulnessbased intervention.

Masih sedikit penelitian meta-analisis yang secara spesifik melihat efektivitas intervensi berbasis mindfulness dalam meningkatkan resiliensi pada individu yang bekerja. Penelitian ini menggunakan pendekatan meta-analisis sebagai metode yang mengintegrasikan berbagai penelitian terdahulu yang menggunakan intervensi berbasis mindfulness untuk meningkatkan resiliensi di tempat kerja.

\section{Metode \\ Partisipan dan desain penelitian}

Partisipan dalam penelitian ini berjumlah 759, yang diperoleh secara akumulatif dari 14 jurnal penelitian. Penelitian ini menggunakan metode metaanalisis. Meta-analisis ini dilakukan dengan menggabungkan hasil data dari penelitian terdahulu. Kualitas dari penelitian terdahulu yang digunakan dapat mempengaruhi hasil dari penelitian meta analisis ini.

\section{Prosedur dan pengukuran}

Sumber data dalam penelitian ini dibatasi pada jurnal internasional dengan intervensi berbasis mindfulness untuk meningkatkan resiliensi pada individu yang bekerja. Penelitian ini menggunakan kriteria jurnal yang diterbitkan dalam rentang waktu 10 tahun terakhir.

Peneliti menelusuri 3 database elektronik seperti Google Scholar, Researchgate, dan Sciencedirect. Pencarian dilakukan dengan menggunakan kata kunci mindfulness intervention, resilience dan employee atau worker. Terdapat 47.500 artikel dan buku yang terkait kata kunci tersebut, yang selanjutnya peneliti saring berdasarkan tahun penerbitan yaitu 20112020, yang membuahkan 16.900 hasil pencarian. Pencarian kemudian dilanjutkan dengan menyaring penelitian tersebut berdasarkan metode penelitian yang digunakan. Dari seleksi yang dilakukan, ditemukan 1.400 artikel penelitian yang menggunakan intervensi berbasis mindfulness dengan alat ukur resiliensi dengan responden yang bekerja. Penelitian yang diperoleh tersebut kemudian diperiksa kembali berdasarkan kelengkapan yang dimiliki, yang terdiri dari (1) karakter studi (tahun publikasi, prosedur, desain penelitian, dan jenis kontrol), (2) karakteristik peserta (ukuran sampel untuk kelompok intervensi dan kontrol, dan profesi responden), (3) karakteristik intervensi (jenis intervensi, lama intervensi).

Pada penelitian ini, peneliti melihat effect size dengan melihat nilai rata-rata $(M)$, deviasi standar $(S D)$ serta ukuran sampel $(N)$ pada hasil setelah dilakukannya intervensi dari setiap kelompok menggunakan aplikasi Meta-Mar versi $2.7 .0 \quad$ (n.d.). Statistik $I^{2}$ 
digunakan untuk memeriksa heterogenitas, dimana nilai inconsistency $\left(I^{2}\right)$ terbagi menjadi tiga kategori yaitu rendah $\left(I^{2} \leq\right.$ $25 \%)$, sedang $\left(I^{2} \pm 50 \%\right)$, dan tinggi $\left(I^{2} \geq\right.$ $75 \%$ ) (Card, 2012). Nilai I ${ }^{2}$ dalam penelitian ini adalah $32 \%$ atau termasuk dalam kategori sedang sehingga peneliti disarankan untuk menggunakan random effect size model.

Gambar 1. Skema Alur Identifikasi Jurnal.

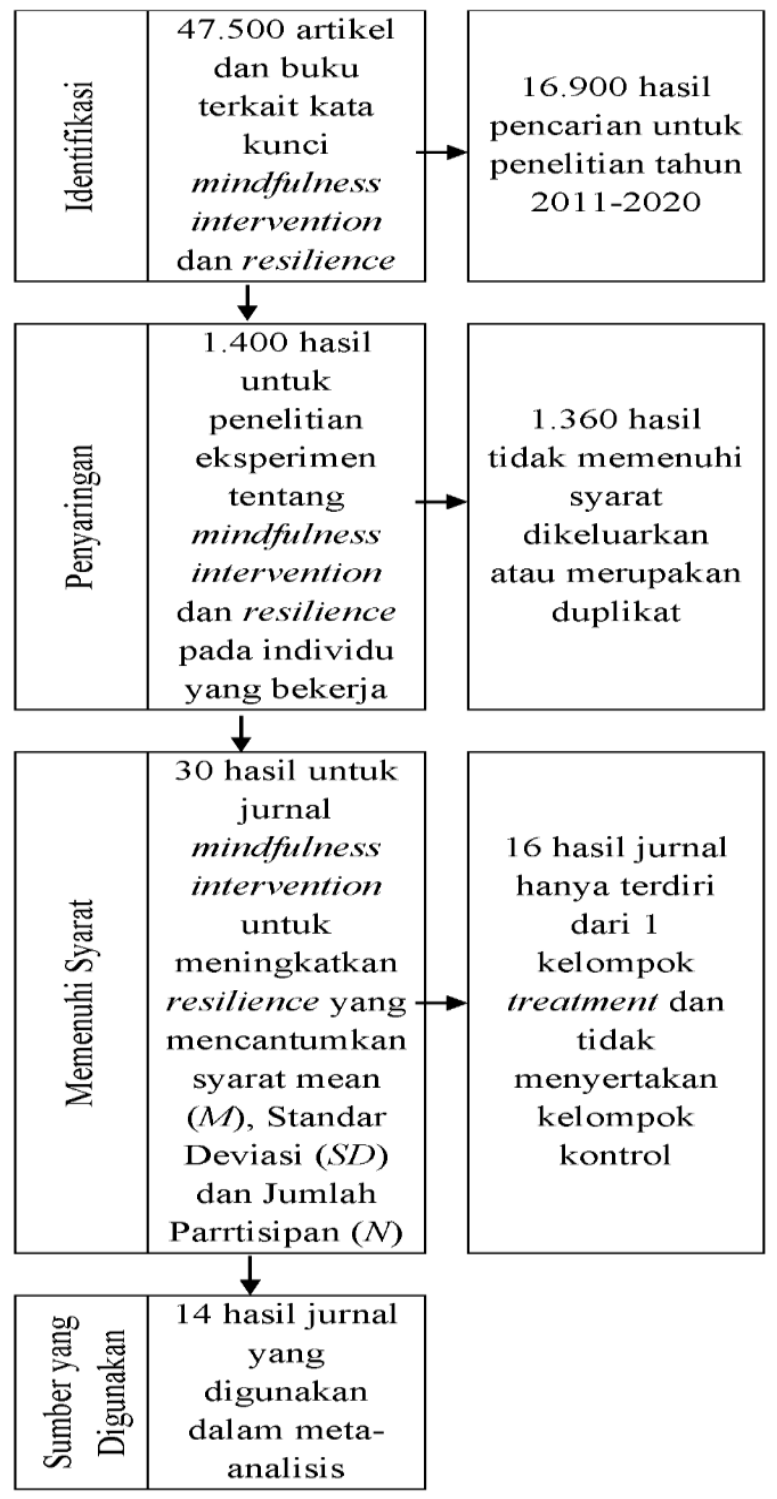

Gambar 2. Forrest Plot.

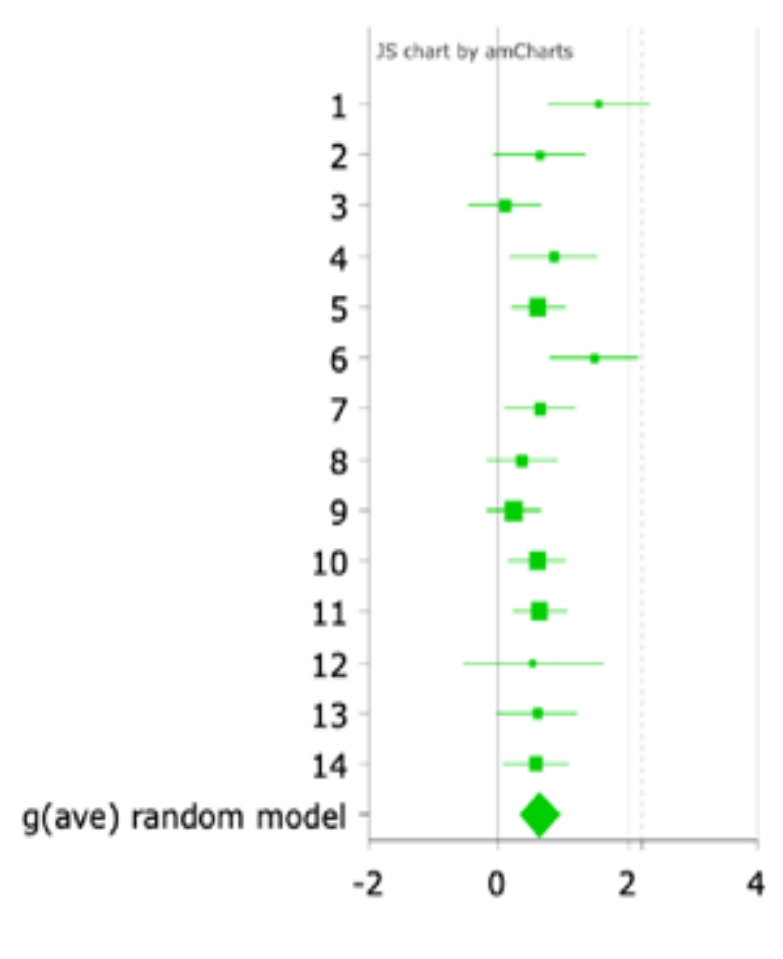

Gambar 3. Funnel Plot.

Funnel Plot random model (Y: Standard Error (SEg) - X: Effect Size (g))

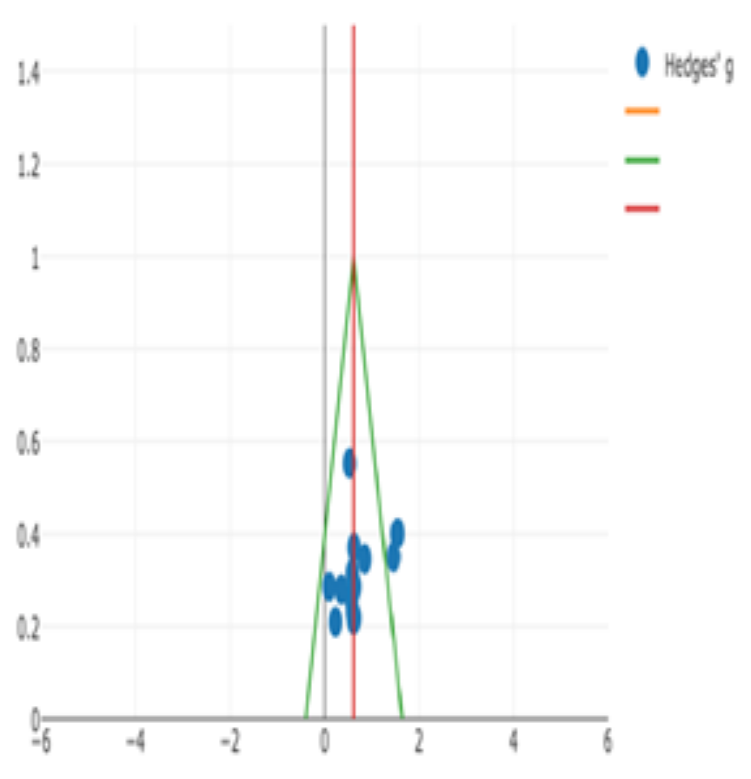




\section{Hasil}

Penelitian ini dilakukan dengan menggunakan 14 studi jurnal dengan jumlah responden sebanyak 759 responden, dengan tujuan menguji efektivitas intervensi mindfulness untuk meningkatkan relisiensi di tempat kerja. Enam penelitian berasal dari Amerika, tiga penelitian berasal dari Asia, tiga penelitian berasal dari Eropa, dan dua penelitian berasal dari Australia.

Hasil analisis menunjukkan nilai inconsistency sebesar 32\% yang bermakna bahwa heterogenitas penelitian ini tergolong dalam kategori sedang, sehingga peneliti menggunakan nilai Hedges'g (SMD) pada random effect model. Selain itu, peneliti juga membertimbangkan adanya perbedaan alat ukur dan jenis mindfulness yang digunakan, yang semakin memperkuat hal tersebut. Nilai effect size yang digunakan adalah nilai Hedges'g (SMD) pada random effect model sebesar 0.62 (95\% $\mathrm{CL}=0.43$ sampai 0.80). Effect size terbagi kedalam 3 kategori antara lain kecil $(\mathrm{g} \leq 0.2)$, sedang $(\mathrm{g} \pm 0.5)$ dan besar $(\mathrm{g} \geq 0.8)$. Berdasarkan kategori tersebut, effect size penelitian ini tergolong dalam kategori sedang. Mengacu pada hasil tersebut maka intervensi berbasis mindfulness memberikan efek yang sedang atau kurang signifikan dalam meningkatkan resiliensi individu yang bekerja. Tabel 1 di bawah ini menampilkan random effect model berdasarkan hasil analisis dari jurnal-jurnal yang digunakan dalam meta-analisis.

Tabel 1. Effect Size Analisis Hasil Studi.

\begin{tabular}{|c|c|c|c|c|c|c|c|c|}
\hline \multirow{2}{*}{ No. } & \multirow{2}{*}{ Peneliti } & \multirow{2}{*}{ Metode } & \multirow{2}{*}{$\begin{array}{l}\text { Alat } \\
\text { ukur }\end{array}$} & \multirow{2}{*}{$n$} & \multicolumn{4}{|c|}{ Effect size } \\
\hline & & & & & $\mathrm{g}$ & $S E g$ & g lower & $g$ upper \\
\hline 1 & $\begin{array}{l}\text { Colgan dkk. } \\
(2019)\end{array}$ & MBWR & BRS & 31 & 1.54 & 0.40 & 0.76 & 2.33 \\
\hline 2 & $\begin{array}{l}\text { Schroeder dkk. } \\
\text { (2016) }\end{array}$ & MBI & BRS & 29 & 0.63 & 0.37 & -0.09 & 1.35 \\
\hline 3 & Nila dkk. (2016) & MBSR & BRS & 49 & 0.09 & 0.27 & -0.46 & 0.65 \\
\hline 4 & $\begin{array}{l}\text { Czerwinski dkk. } \\
(2020)\end{array}$ & $\begin{array}{l}\text { Mindfulness } \\
\text { Based } \\
\text { Colouring }\end{array}$ & $\begin{array}{l}\text { CD- } \\
\text { RISC }\end{array}$ & 25 & 0.86 & 0.34 & 0.17 & 1.53 \\
\hline 5 & Aikens dkk. (2014) & $\begin{array}{c}\text { Mindfulness } \\
\text { Resilience } \\
\text { Program }\end{array}$ & $\begin{array}{l}\text { CD- } \\
\text { RISC }\end{array}$ & 89 & 0.61 & 0.21 & 0.19 & 1.03 \\
\hline 6 & $\begin{array}{l}\text { Movassagh dkk. } \\
\text { (2019) }\end{array}$ & MIM & $\begin{array}{l}\text { CD- } \\
\text { RISC }\end{array}$ & 40 & 1.46 & 0.35 & 0.77 & 2.15 \\
\hline 7 & $\begin{array}{l}\text { Christopher dkk. } \\
\text { (2018) }\end{array}$ & MBRT & $\begin{array}{l}\text { CD- } \\
\text { RISC }\end{array}$ & 50 & 0.64 & 0.26 & 0.13 & 1.14 \\
\hline 8 & Slatyer dkk. (2017) & MSCR & $\begin{array}{l}\text { CD- } \\
\text { RISC }\end{array}$ & 76 & 0.36 & 0.28 & -0.18 & 0.90 \\
\hline
\end{tabular}


Tabel 1. (lanjutan).

\begin{tabular}{|c|c|c|c|c|c|c|c|c|}
\hline \multirow{2}{*}{ No. } & \multirow{2}{*}{ Peneliti } & \multirow{2}{*}{ Metode } & \multirow{2}{*}{$\begin{array}{l}\text { Alat } \\
\text { ukur }\end{array}$} & \multirow{2}{*}{$n$} & \multicolumn{4}{|c|}{ Effect size } \\
\hline & & & & & $g$ & $S E g$ & g lower & $g$ upper \\
\hline 9 & Lin dkk. (2018) & MBSR & $\begin{array}{l}\text { CD- } \\
\text { RISC }\end{array}$ & 90 & 0.23 & 0.21 & -0.17 & 0.64 \\
\hline 10 & Denkova dkk. (2020) & MBAT & $\begin{array}{l}\text { CD- } \\
\text { RISC }\end{array}$ & 78 & 0.59 & 0.23 & 0.14 & 1.05 \\
\hline 11 & Jung dkk. (2016) & MBT & $\begin{array}{l}\text { CD- } \\
\text { RISC }\end{array}$ & 87 & 0.64 & 0.21 & 0.21 & 1.06 \\
\hline 12 & $\begin{array}{l}\text { Crowder dan Sears } \\
\text { (2016) }\end{array}$ & MBSR & EQ & 12 & 0.53 & 0.55 & -0.54 & 1.61 \\
\hline 13 & $\begin{array}{l}\text { Hanna dan Pidgeon } \\
\text { (2018) }\end{array}$ & MBI & RQS & 41 & 0.59 & 0.31 & -0.02 & 1.21 \\
\hline 14 & $\begin{array}{l}\text { Champion dkk. } \\
\text { (2018) }\end{array}$ & MM & WRS & 62 & 0.56 & 0.26 & 0.07 & 1.08 \\
\hline
\end{tabular}

Keterangan. MBWR: Mindfulness based Wellness and Resilience; MBI: Mindfulness based Intervention; MBSR: Mindfulness based Stress Reduction; MIM: Mindfulness in Motion-based; MBRT: Mindfulness based resilience training; MBAT: Mindfulness based Attention Training; MBT: Mind Body Training; MM: Mindfulness Meditation; BRS: The Brief Resilience Scale; CD-RISC: Conor Davidson Resilience Scale; EQ: Experiences Questionairen; RQS: The Resilience Quotient Scale; WRS: The Wagnild Resilience Scale; $g$ = effect size hedges' $g$, SEg = standard error effect size hedges' $g$.

Berdasarkan hasil uji analisis menggunakan 14 studi jurnal (dapat dilihat pada Tabel 1) dengan random effect model untuk mengeksplorasi efek intervensi berbasis mindfulness pada resiliensi, diperoleh nilai Hedge $g$ sebesar 0.62, yang berarti bahwa intervensi mindfulness memiliki medium effect size terhadap peningkatan resiliensi. Persentase jumlah penelitian yang menunjukkan adanya large effect size dari mindfulness terhadap resiliensi adalah sebanyak $21 \%$, penelitian dengan tingkat effect size medium to high adalah sebanyak $71 \%$ dan low to medium sebanyak 7\%. Hal ini menunjukkan bahwa intervensi mindfulness kurang efektif dalam peningkatan resiliensi. Kurang signifikannya efektivitas ini dapat disebabkan oleh beberapa faktor. Hasil tersebut kemungkinan MEDIAPSI | 2021, Vol. 7, No. 1, 27-36 diperoleh karena adanya variasi dalam alat ukur dan intervensi yang digunakan dalam penelitian ini.

Berdasarkan hasil meta-analisis, diketahui bahwa intervensi berbasis mindfulness berpeluang meningkatkan resiliensi yang dimiliki oleh individu yang bekerja, walaupun tidak dapat dikatakan signifikan. Mindfulness merupakan intervensi berbasis kognitif untuk meningkatkan perhatian secara penuh terhadap sesuatu tanpa perlu memberikan penilaian (Spiegler \& Guevremont, 2010). Hasil dari meta analisis yang dapat dipengaruhi oleh perbedaan jenis intervensi mindfulness tersebut mengindikasikan bahwa intervensi ini perlu dicermati lebih lanjut dari segi skala relisiensi yang digunakan. 
Sebagian besar skala resiliensi yang ada mengukur resiliensi sebagai sifat kepribadian yang stabil atau fokus pada penilaian ketersediaan sumber daya yang dapat membantu individu untuk mempertahankan atau mendapatkan kembali resiliensi ketika mengalami kesulitan, seperti Connor-Davidson Resilience Scale (Connor \& Davidson, 2003). Skala lainnya, The Brief Resilience Scale (BRS) mengukur resiliensi sebagai kemampuan untuk pulih dari stres dan tidak menilai faktor yang mungkin mendukung dalam mempertahankan atau mendapatkan kembali resiliensi saat mengalami kesulitan (Smith dkk., 2008).

Menurut Masten (2001), resiliensi seseorang dapat diukur hanya ketika individu tersebut sedang mengalami stres atau trauma. Apabila responden dalam penelitian tidak mengalami stres ataupun trauma dalam pekerjaan, maka peningkatan resiliensi yang didapatkan akan kurang signifikan. Selanjutnya beberapa penelitian yang digunakan dalam penelitian metaanalisis ini memiliki jumlah responden yang relatif kecil. Menurut Colgan dkk. (2019), ukuran sampel yang kecil dapat mengurangi generalisasi temuan, sehingga memungkinkan terjadinya bias. Ukuran sampel yang kecil dapat mengurangi kekuatan statistik dan kesulitan dalam mendeteksi peningkatan pada hasil (Schroeder dkk., 2015).

Berdasarkan hasil analisis, mindfulness memberikan dampak yang kurang signifikan dalam meningkatkan resiliensi individu yang bekerja. Hal tersebut dapat dilihat dari hasil analisis heterogenitas dan effect size correlation yang termasuk dalam kategori sedang, yang mengindikasikan bahwa intervensi ini perlu diteliti lebih lanjut untuk menemukan faktor penyebabnya. Hasil yang sedang ini mungkin karena inkonsistensi dalam ukuran studi dan variasi desain intervensi (Spinelli dkk., 2019). Pada beberapa penelitian jumlah peserta dalam penelitian berkurang dari jumlah yang ditentukan. Selain itu, perlu untuk mempertimbangkan penggunaan intervensi lain dalam meningkatkan resiliensi individu yang bekerja.

Penelitian ini memiliki sejumlah kelemahan. Pertama, jenis intervensi berbasis mindfulness yang digunakan terdiri dari beberapa jenis. Kedua, alat ukur resiliensi yang digunakan terbagi ke dalam empat jenis, yaitu BRS, CD-RISC, RQS dan WRS. Kelemahan pada penelitian ini dapat menjadi pertimbangan bagi peneliti selanjutnya yang ingin meninjau lebih dalam mengenai intervensi berbasis mindfulness dan pengaruhnya dalam meningkatkan resiliensi untuk melakukan beberapa Langkah. Pertama, peneliti berikutnya perlu mengeksplorasi aspek kesehatan lainnya termasuk fisik dan kesejahteraan. Kedua, peneliti berikutnya perlu memasukkan pengukuran mindfulness dan catatan mengenai meditasi yang dilakukan seperti durasi, gaya dan kualitas praktik. Ketiga, peneliti berikutnya perlu mempertimbangkan tingkat stres responden penelitian, karena pengukuran resiliensi akan menunjukkan hasil yang lebih signifikan pada responden yang mengalami stres ataupun trauma.

\section{Kesimpulan}

Intervensi berbasis mindfulness kurang efektif meningkatkan relisiensi kerja dalam studi meta-analisis ini, yang memberikan dua implikasi. Pertama, diperlukannya identifikasi dan pengujian faktor-faktor yang membatasi efektivitas tersebut, yang secara metodologis disebut 
sebagai variabel moderator, seperti perbedaan konteks sosial-budaya. Kedua, diperlukannya identifikasi dan pengujian faktor-faktor yang secara logis menjadi alasan kurang optimalnya efek intervensi berbasis mindfulness dalam meningkatkan resiliensi kerja, yang secara metodologis disebut sebagai variabel mediator.

\section{Daftar Pustaka}

Aherne D., Farrant, K., Hickey, L., Hickey, E., McGrath, L., \& McGrath, D. (2016). Mindfulness based stress reduction for medical students: Optimising student satisfaction and engagement. BMC Medical Education, 16(1), 1-11. https://doi.org/10.1186/s12909-0160728-8

Aikens K. A., Astin J., Pelletier K. R., Levanovich, K., Baase, C. M., Park, Y. Y., \& Bodnar, C. M. (2014). Mindfulness goes to work: Impact of an online workplace intervention. $J$ Occup Environ Med, 56, 721-31. https://doi.org/10.1097/JOM.00000000 00000209

Bajaj, B., \& Pande, N. (2016). Mediating role of resilience in the impact of mindfulness on life satisfaction and affect as indices of subjective wellbeing. Personality and Individual Differences, 93, 63-67. https://doi.org/10.1016/j.paid.2015.09. 005

Barrat, C. (2018). Developing resilience: The role of nurses, healthcare teams and organisations. Nursing Standard, 33, 43-49. https://doi.org/ 10.7748/ns.2018.e11231

Burton, A., Burgess, C., Dean, S., Koutsopoulou, G. Z., \& Jones, S. H.
(2017). How effective are mindfulness-based interventions for reducing stress among healthcare professionals? A systematic review and meta-analysis. Stress and Health, 33 , 3-13. https://doi.org/10.1002/smi.2673

Card, N. A. (2012). Applied meta-analysis for social science research. Guilford Press.

Champion, L., Economides, M., \& Chandler, C. (2018). The efficacy of a brief appbased mindfulness intervention on psychosocial outcomes in healthy adults: A pilot randomised controlled trial. Plos One, 13(12), Article e0209482.

https://doi.org/10.1371/journal.pone.02 09482

Christopher, M. S., Hunsinger, M., Goerling R. J., Bowen, S., Rogers, B. S., Gross, C. R., Dapolonia, E., \& Pruessner, J. C. (2018). Mindfulness-based resilience training to reduce health risk, stress reactivity and aggression among law enforcement officers: A feasibility and preliminary efficacy trial. Psychiatry Research, 264, 104115 .

https://doi.org/10.1016/j.psychres.2018 .03 .059

Colgan, D. D., Christoper, M., Bowen, S., Brems, C., Hunsinger, M., Tucker, B., \& Dapolonia, E. (2019). Mindfulnessbased wellness and resilience intervention among interdisciplinary primary care teams: A mixed methods feasibility and acceptability trial. Primary Health Care Research \& Development, 20, 1-8. https://doi.org/10.1017/S14634236190 00173 
Connor, K. M., \& Davidson, J. R. (2003). Development of a new resilience scale: The Connor-Davidson Resilience Scale (CD-RISC). Depress Anxiety, $18(2)$, 76-82. https://doi.org/10.1002/da.10113

Crowder, R., \& Sears, A. (2016). Building resilience in social workers: An exploratory study on the impacts of a mindfulness-based intervention. Australian Social Work, 70(1), 17-29. https://doi.org/10.1080/0312407X.201 6.1203965

Czerwinski N., Egan, H., Cook, A., \& Mantzios, M. (2020). Teachers and mindful colouring to tackle burnout and increase mindfulness, resiliency and wellbeing. Contemporary School Psychology, Advance online publication.

https://doi.org/10.1007/s40688-02000279-9

Denkova, E., Zanesco, A. P., Rogers, S. L., \& Jha, A. P. (2020). Is resilience trainable? An initial study comparing mindfulness and relaxation training in firefighters. Psychiatry Research, 285, $1-8$.

https://doi.org/10.1016/j.psychres.2020 .112794

Fletcher, D., \& Sarkar, M. (2013). Psychological resilience: A review and critique of definitions, concepts, and theory. European Psychologist, 18(1), 12-23. https://doi.org/10.1027/10169040/a000124

Hanna, A., \& Pidgeon, A. M. (2018). Leveraging mindfulness to build resilience and professional quality of life in human service professionals. OBM Integrative and Complementary Medicine, 3(2), 2-21. https://doi.org/10.21926/obm.icm.1802 007

Hartwig, A., Clarke, S., Johnson, S., \& Willis, S. (2020). Workplace team resilience: A systematic review and conceptual development. Organizational Psychology Review, 10(3-4), 169-200. https://doi.org/10.1177\%2F204138662 0919476

Huang, S. L., Li, R. H., Huang, F. Y., \& Tang, F. C. (2015). The potential for mindfulness-based intervention in workplace mental health promotion: Results of a randomized controlled trial. Plos One, 10(9), Article e0138089.

https://doi.org/10.1371/journal.pone.01 38089

Johnson, K. R., Park, S., \& Chaudhuri, S. (2020). Mindfulness training in the workplace: Exploring its scope and outcomes. European Journal of Training and Development, 44(45), 341-354.

https://doi.org/10.1108/EJTD-092019-0156

Jung, Y. H., Ha, T. M., Oh, C. Y., Lee U. S., Jang, J. H., Kim, J., Park, J. O., \& Kang, D. H. (2016). The effects of an online mind-body training program on stress, coping strategies, emotional intelligence, resilience and psychological state. PlosOne, 11(8), Article e0159841. https://doi.org/10.1371/journal.pone.01 59841

Kersemaekers, W., Rupprecht, S., Wittmann, M., Tamdjidi, C., Falke, P., Donders, R., \& Speckens, K. N. (2018). A workplace mindfulness intervention may be associated with improved 
psychological well-being and productivity: A preliminary field study in a company setting. Frontiers in Psychology, $\quad 9$ : 195. https://doi.org/10.3389/fpsyg.2018.001 95

Lin, L., He, G., Yan, J., Gu, C., \& Xie, J. (2019). The effects of a modified mindfulness-based stress reduction program for nurses. Workplace Health \& Safety, 67(3), 111-121. https://doi.org/10.1177/216507991880 1633

Lomas, T., Medina, J. C., Ivtzan, I., Rupprecht, S., \& Eiroa-Orosa, F. J. (2019). Mindfulness-based interventions in the workplace: An inclusive systematic review and metaanalysis of their impact upon wellbeing. The Journal of Positive Psychology, 14(5), 625-640. https://doi.org/10.1080/17439760.2018 .1519588

Masten, A. S. (2001). Ordinary magic: Resilience processes in development. American Psychologist, 56(3), 227238. https://doi.org/10.1037/0003066X.56.3.227

Meta-Mar. (n.d.). Meta-Mar (Version 2.7.0) [Internet software]. https://www.metamar.com/

Movassagh, M. T., Arshadi, N., Bassaknejad, S., \& Beshlideh, K. (2019). The effect of mindfulness in motion-based training on resiliency, emotion regulation, and job stress. Journal of Occupational Health and Epidemiology, $\quad 8(1), \quad 49-55$. http://doi.org/10.29252/johe.8.1.49

Nila, K., Holt, D. V., Ditzen, B., \& Raab, C. G. (2016). Mindfulness-based stress reduction (MBSR) enhances distress tolerance and resilience through changes in mindfulness. Mental Health \& Prevention, 4, 36-41. https://doi.org/10.1016/j.mhp.2016.01. 001

Schroeder, D. A., Stephens, E., Colgan, D., Hunsinger, M., Rubin, D., \& Christopher, M. S. (2016). A brief mindfulness-based intervention for primary care physicians: A pilot randomized controlled trial. Am $J$ Lifestyle Med, 12(1), 83-91. https://doi.org/10.1177\%2F155982761 6629121

Slatyer, S., Craige, M., Heritage, B., Davis, S., \& Rees, C. (2018). Evaluating the effectiveness of a brief mindful selfcare and resiliency (MSCR) intervention for nurses: A controlled trial. Mindfulness, 9, 534-546. https://doi.org/10.1007/s12671-0170795-x

Smith, B. W., Dalen, J., Wiggins, K., Tooley, E., Christopher, P., \& Bernard, J. (2008). The brief resilience scale: Assessing the ability to bounce back. International Journal of Behavioral Medicine, 15(3), 194-200. https://doi.org/10.1080/107055008022 22972

Spiegler, M. D., \& Guevremont, D. C. (2010). Contemporary behavior therapy. Wadsworth/Cengage Learning.

Spinelli, C., Wisener, M., \& Khoury, B. (2019). Mindfulness training for healthcare professionals and trainees: A meta-analysis of randomized controlled trials. Journal of Psychosomatic Research, 120, 29-38. https://doi.org/10.1016/j.jpsychores.20 19.03.003 